\title{
THE FUNDAMENTAL ASPECTS OF INFORMATION SUPPORT FOR POPULATION PROTECTION FROM THE PERSPECTIVE OF MUNICIPALITIES WITH EXTENDED POWERS IN THE CZECH REPUBLIC
}

\author{
RAK, J[akub]; JASEK, R[oman]; ADAMEK, M[ilan] \& JURIKOVA, L[ucie]
}

\begin{abstract}
The contribution introduces the field of information support for the population protection. In particular, it focuses on a definition of a basic structure of an information system for planning and implementation of the population protection in the context of the valid legislation and possible practical application in the territory of the municipality with extended powers
\end{abstract}

Key words: information systems, population protection, crisis management, information support

\section{INTRODUCTION}

Protection of population together with crisis management represents the basic elements for the provision of the protection of life, health and property of the population and state authorities. Therefore, it is necessary to create the operational information system (IS) for the support of management and planning for protection of the population. The information support must meet fundamental requirements placed by various users and simultaneously ensure high information security and easy operation together with maximum transparency and user friendliness.

A similar support has been employed in the Czech Republic (CR) for some time. However, it is highly extensive and it contains several fundamental weaknesses, which reduces its utility value. In spite of this, it has achieved the best results in practical use from a global perspective. This is mainly caused by the quality legislative basis on which the functionality of the information system (of information support) and generally the system of population protection (PP) are dependant. Another equally essential element is the staff. The staff can have either a positive or negative impact, particularly by means of the inconsistent (non-system) approach and from this resulting inconsistent use of the information system (IS). The non-system approach represents the most severe deficiency in the IS for planning, management and implementation of the PP in the CR. There is, in particular, a different approach towards processing documents necessary for planning, preparation and actual implementation of the PP. Another issue is an inconsistent level of knowledge and skills of individual employees performing tasks of the provision of the PP.

From the viewpoint of the IS it is important to mention a direct connection to the population, which is in some cases of extraordinary events and crisis states rather troublesome and inefficient.

\section{BACKGROUND FACTS AND REQUIREMENTS}

Current information support (IS) is based on valid legislation of the Czech Republic. In particular, it is (***2011):

- Concept of protection of the population by the year 2013 until 2020

- Act No. 240/2000 Coll., "the Crisis Act"
- Act No. 239/2000 Coll., "On the integrated emergency system"

- Regulation No. 380/2002 Coll., "on preparation and execution of tasks concerning the protection of the population", Etc.

Based on the above mentioned standards the basic elements of the implementation of the PP can be determined; these elements are municipalities, municipalities with extended powers, regional authorities, government of the $\mathrm{CR}$ and their mutual relationships. By virtue of these structures and mutual relations defined in these documents the information support in the CR is created focusing on 9 fundamental areas of the PP, namely:

- Warning;

- Evacuation;

- Sheltering;

- Emergency survival;

- Protection from contamination;

- Humanitarian aid;

- Cooperation with noneprofit organisations;

- Monitoring of radiological, chemical and biological situation;

- Population notifying (Kovarik, 2006).

For individual areas methods of their provision, including information support are stated in detail. These basic documents give municipalities and municipalities with extended powers (MEP) a certain freedom in the field of document preparation and planning of the PP.

In addition, there is a wide range of IS intended for crisis management support, which are directly related to the PP. However, these IS are rather complex and unpopular from the perspective of employees.

\section{DEFINITION OF THE INFORMATION SYSTEM FOR POPULATION PROTECTION}

The IS for the PP composes of several basic elements. First, it should be noted that the complex system is intended for creation, transfer and employment of information. Therefore, its objective is not only the provision, transfer and processing of information but predominantly simplification and standardisation of work processes.

In its general form each IS serves for collection, transfer, maintenance, processing and providing information and data. Nevertheless, the field of PP places rather broad requirements on the IS.

The main elements of the structure of the IS suitable for planning, management and implementation of PP are:

- Sensor - sensoric systems;

- Information transfer - transfer system;

- Information gathering and sorting;

- User - a higher level (regions and MEP); 
- User - a lower level (municipalities, population, IRS units);

- Feedback.

The mutual bonds of the individual elements are depicted in Fig. 1.

The proposal of the IS structure for planning and implementation of PP is inspired by an IS for management and control of combat. The crucial areas of the whole IS are clearly defined requirements on individual subjects, their feedback to superior subjects and correct information readiness of the employees involved in the process of PP (IS users) (Stair, 2003).

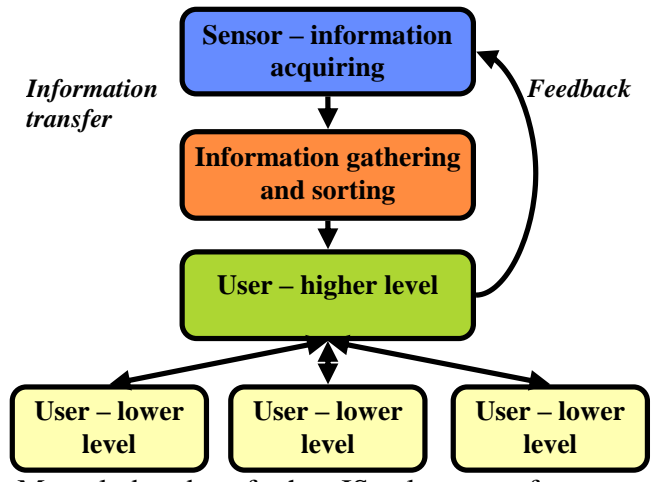

Fig. 1. Mutual bonds of the IS elements for support of population protection management

\section{THE NEED FOR INFORMATION SUPPORT IN THE FIELD OF POPULATION PROTECTION IN ORP PERSPECTIVE - STRUCTURE IS}

When determining the structure and relationships of IS the method of analysis and synthesis of available information was employed. This method was appropriately supplemented by results of research and observations of practical applications of currently employed information support.

Based on the cooperation with the MEP Zlín several basic requirements placed by the municipality employees on the IS for PP were determined. With the aid of these requirements the structure of the information support process depicted in the Fig. 2 could have been proposed.

The main participants of the process of the information support for PP and their mutual relationships and tasks led to the structure proposal. The main participants are:

- Regions;

- Municipalities with extended powers;

- Municipalities;

- Population;

- Units of the Integrated Rescue System (IRS).

The main tasks are defined in "Concept of protection of the population" (see Chapter 2).

The IS consists of "modules" ( 9 basic tasks being fulfilled depending on the legislation), "subjects" (regions, MEP, municipalities and population) and IRS (units of the Integrated Rescue System - predominantly police, fire brigade, emergency service etc.). These elements are in the whole process supported by software (mainly GIS, web applications, or special software tools). There is a data output at the end of the information process (preferably through visualisation, ensuring easier understanding).

\section{PLANNED ACTIVITIES}

In conjunction with the MEP Zlín a gradual implementation of the IS is planned. The implementation process is preceded by the creation of individual modules ( 9 basic modules). Currently, the implementation of the first test shelter module is in progress
(Jurikova, 2010). Prior to implementation of each module an extensive analysis is performed and there are also eventual modifications of its structure, methods of its functions and requirements.

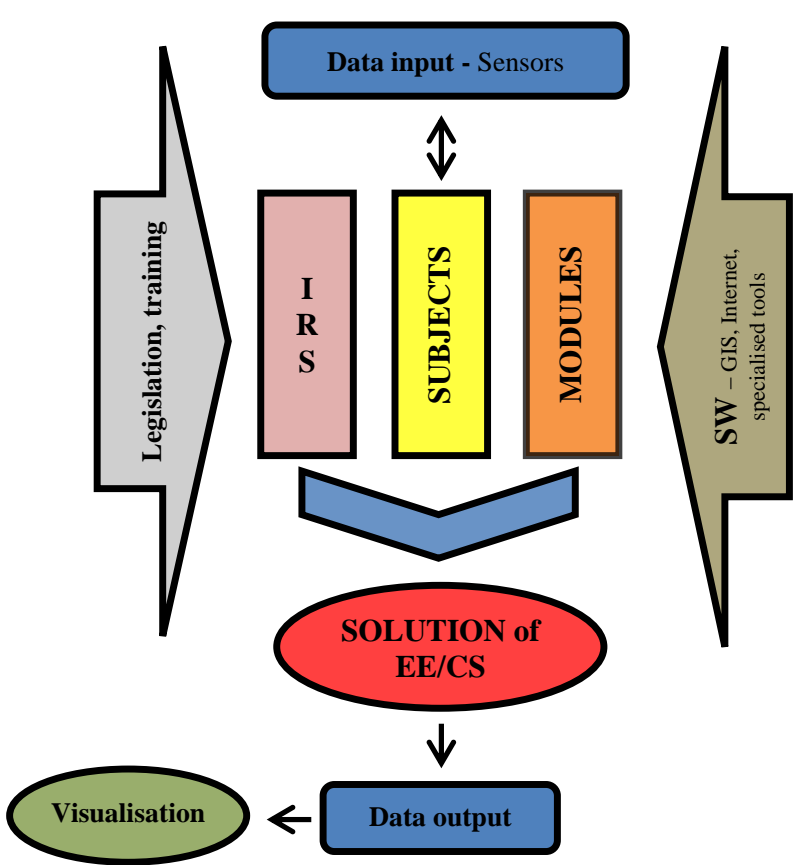

Fig. 2. The structure of the public protection information system (Hanak, 2004)

\section{CONCLUSION}

Simplicity is one of the most important characteristics of the IS and in order to ensure its functionality it is necessary to define methods of its utilisation. This is respected in the proposed IS structure which comprises of all legal requirements and which tries to simplify and interlink them. On the grounds of a limited extent of the article the IS structure is introduced in a rudimentary form only. In a practical application it is specified in both the vertical and horizontal levels. Today, verification of functionality of the proposed IS is in progress through the implementation of one of the modules, "the shelter module". The main contributions of the proposed IS implementation are predominantly the provision of unified approaches of the subjects and simplification of their work.

\section{ACKNOWLEDGEMENTS}

This article has been supported by grant of IGA University of Thomas Bata in Zlin, Faculty of Applied informatics, number IGA/46/FAI/10/D and IGA/38/FAI/11/D.

\section{REFERENCES}

Hanak, J. (2004); http://www.systemonline.cz/clanky/informac ni-system-pro-podporu-krizoveho-rizeni.htm - Information support for crisis management, Systém online, Accessed on: 2011-07-15

Jurikova, L., Rak, J \& Adamek, M. (2010) Proposal for technology of improvised shelters design in conditions of the Czech republic, Annals of DAAAM for 2010 \& Proccedings of the 21 st International DAAAM Symposium, Austria - Vienna: DAAAM International 2010. p. 1337. ISBN 978-3-901509-73-5

Kovarik, J. \& Smetana, M. (2006); Fundamentals of Civil Protection, SPBI, ISBN 86634-85-X, Ostrava

Stair, R. \& Reynolds. G. (2003) Principles of Information Systems, Thomson/Course Technology, ISBN 0619064897, Boston

*** (2011) Full text no. 823 - emergency laws, Sagit, pg.304 